\title{
Enzyme-Loaded Catalytic Macrophage Vesicles with Cascade Amplification of Tumor-Targeting for Oxygenated Photodynamic Therapy
}

\author{
Ling Liu' ${ }^{1} *$ \\ Jiayu Zhang ${ }^{2, *}$ \\ Zinan $\mathrm{Li}^{3}$ \\ Yang Yang ${ }^{4}$ \\ Longyun $\mathrm{Li}^{3}$ \\ Yuyang Zhao ${ }^{5}$ \\ Jia Zhao ${ }^{3}$ \\ 'Department of Pediatrics, China-Japan \\ Union Hospital of Jilin University, \\ Changchun, Jilin, People's Republic of \\ China; ${ }^{2}$ Department of Gastrointestinal \\ Colorectal and Anal Surgery, China-Japan \\ Union Hospital of Jilin University, \\ Changchun, Jilin, People's Republic of \\ China; ${ }^{3}$ Department of Anesthesiology, \\ China-Japan Union Hospital of Jilin \\ University, Changchun, Jilin, People's \\ Republic of China; ${ }^{4}$ Department of \\ Oncology and Hematology, China-Japan \\ Union Hospital of Jilin University, \\ Changchun, Jilin, People's Republic of \\ China; ${ }^{5}$ Department of Gastroenterology \\ and Hepatology, China-Japan Union \\ Hospital of Jilin University, Changchun, \\ jilin, People's Republic of China
}

*These authors contributed equally to this work

Correspondence: Jia Zhao

Department of Anesthesiology, ChinaJapan Union Hospital of Jilin University, Changchun, Jilin, People's Republic of

China

Email zj54I3@jlu.edu.cn

Yuyang Zhao

Department of Gastroenterology and Hepatology, China-Japan Union Hospital of Jilin University, Changchun, Jilin,

People's Republic of China

Email zhaoyuyang@jlu.edu.cn
Background: Realizing that the potential of photodynamic therapy (PDT) is hindered by hypoxic microenvironment of tumor section, it is desirable to provide a cascade oxygenation strategy to enhance PDT.

Methods: The hydrophilic catalase protein was covalently linked to the hydrophobic photosensitizer Ce6 to form the nanocomplex Catalase-Ce6 with self-assembly. And the Catalase-Ce6 was loaded in the M1 macrophage vesicles (EVs) with GOX-modified to construct the nanosystem Catalase-Ce6@MEVs. The synergistic effects of PDT induced by Catalase-Ce6@MEVs were evaluated on the subcutaneous MFC tumor model.

Results: The construction of Catalase-Ce6 not only solved the insoluble problem of Ce6, but also induced a cascade effects for hydrolyzing glucose and increasing the hydrogen peroxide content, achieving the purpose of oxygenated PDT. Cascade tumor targeting was also realized through the binding between vascular cell adhesion molecule 1 (VCAM-1) of tumor tissue and $\alpha 4$ integrin of EVs and enhanced vascular permeability, triggering by PDT. Besides, in vivo experiments found that the Catalase-Ce6@MEVs presented M2 macrophage polarization effect.

Conclusion: Catalase-Ce6@MEVs exhibit the cascade targeting ability after laser irradiation and prominent tumor treatment effect in vivo, which may provide new ideas and methods for targeted PDT in clinical practice.

Keywords: photodynamic therapy, cascade oxygenation, glucose oxidase, catalase, cascade tumor targeting, macrophage polarization

\section{Introduction}

Photodynamic therapy (PDT) is a clinical therapy that utilizes a photosensitizer, an appropriate excitation light, and oxygen $\left(\mathrm{O}_{2}\right)$ molecules to generate cytotoxic singlet oxygen $\left({ }^{1} \mathrm{O}_{2}\right)$ for eliciting localized and superficial cancers death. ${ }^{1,2}$ Although PDT has emerged as a viable treatment option for different stage cancers, some obstacles in the clinical adoption of PDT persist. One of the major challenges is the concentration of $\mathrm{O}_{2}$ as the hypoxic microenvironment, which is caused by an inadequate $\mathrm{O}_{2}$ supply, being recognized as a characteristic feature of solid tumors. ${ }^{3-6}$ Over the past decade, different strategies to alleviate the hypoxic environment have been tested. Among them, catalase is one of the promising PDT enhancers. ${ }^{7,8}$ As a protein with catalytic activity, it exists in all known tissues of mammals which exhibits excellent biocompatibility. At the same time, the concentration of hydrogen peroxide $\left(\mathrm{H}_{2} \mathrm{O}_{2}\right)$ is relatively high in solid tumor tissues. ${ }^{9,10}$ When catalase is introduced, $\mathrm{O}_{2}$ can be generated and released in 
a relatively short time. Therefore, utilizing catalase to enhance the concentration of $\mathrm{O}_{2}$ molecules is an effective pathway to improve the therapeutic effect of PDT on solid tumors in vivo. Glucose oxidase (GOX) plays an important role in the strategy of cancer starvation therapy which is proposed by depleting the intratumoral glucose to produce $\mathrm{H}_{2} \mathrm{O}_{2} \cdot{ }^{11-14}$ At the same time, $\mathrm{H}_{2} \mathrm{O}_{2}$ is the enzyme hydrolysis substrate of catalase, so GOX can be used in combination with catalase to achieve the purpose of cascading amplification of $\mathrm{O}_{2}$ supply for PDT enhancement.

Extracellular vesicles (EVs) are cell-derived membrane vesicles, which are capable of functionally transferring biological information. ${ }^{15,16}$ EVs can transport biologically active molecules including proteins and nucleic acids which would regulate gene expression and cellular function in target cells. ${ }^{17,18}$ They can also play an immunomodulatory role, either limiting or promoting immune responses, depending on their cellular origin. ${ }^{19,20}$ Furthermore, EVs may have multiple advantages over currently available drug delivery carriers, such as overcoming natural barriers, intrinsic cell targeting properties, and low immunogenicity in the circulation. ${ }^{21}$ Macrophages are important cells of the immune system which can be recruited to tumor sites. ${ }^{22}$ There are a large number of macrophages in tumor microenvironment (TME), ${ }^{23,24}$ which can be divided into M1 and M2 phenotypes. ${ }^{25}$ The two phenotypes play different roles in vivo, such that M1 macrophages are mainly focus on tumor development inhibiting, while M2 macrophages are conducive to tumor growth and metastasis. ${ }^{26,27}$ However, studies have demonstrated that M1 macrophages have the capacity to repolarize M2 macrophages into M1 macrophages by releasing a variety of cytokines, further for reshaping immunosuppressive TME. ${ }^{28,29}$ M1 macrophage vesicles (M1 EVs) are nanoscale cell-derived carriers which enrich RNA, DNA, proteins, and other molecules from parent cells, inheriting some of the functions of the source cells, including M2repolarization ability. ${ }^{30}$ As a natural drug delivery carrier, M1 EVs have advanced characteristics such as active tumor targeting, drug delivery capacity, low immunogenicity and immune activation. Additionally, as macrophages vesicles have the same membrane structure as the parent cell, the active tumor targeting ability could be realized by the combination between alpha 4 integrin ( $\alpha 4)$ of macrophages and vascular cell adhesion molecule 1 (VCAM-1) of tumor tissue. ${ }^{31}$ So, macrophages vesicles can be a kind of ideal tumor targeting drug carrier with bio-membrane structure. Interestingly, at the same time, we found that the inflammatory response induced by PDT could effectively stimulate the further expression of VCAM-1 in tumor tissues. Moreover, PDT has the capacity to damage the microcirculation of tumor tissue, which means it can destroy tumor endothelial cells and increase vascular permeability to promote drug penetration into tumor. ${ }^{33,34}$ These two effects could enhance the internalization of nanoparticles to realize the cascade tumor targeting and improve the therapeutic effect. ${ }^{32}$

Therefore, in this study, the hydrophilic catalase protein was covalently linked to the hydrophobic photosensitizer, Ce6, ${ }^{35}$ and the nanocomplex Catalase-Ce6 was produced with self-assembling in aqueous solution. With loading into the GOX-modified macrophage vesicles, the photodynamic drug delivery nanosystem Catalase-Ce6@MEVs was formed (Scheme 1). The nanocomplex Catalase-Ce6 not only retained the catalytic activity of catalase, but also improved the water solubility of Ce6 which could be applied in vivo. The cascade reaction between GOX and catalase also significantly increased the $\mathrm{O}_{2}$ content in tumor tissue, achieving the oxygenation PDT. It is interesting that Catalase-Ce6@MEVs exhibited a better cascade tumor targeting ability after the laser irradiation, leading to more nanoparticles internalized into the tumor cells. Finally, in the in vivo treatment experiment, Catalase-Ce6@MEVs showed an excellent therapeutic effect and immune activation capacity. Therefore, this study provides a new idea and method for targeted PDT in clinical practice.

\section{Materials and Methods Material}

Ce6 and enzymes (GOX, catalase) were purchased from Shanghai yuanye Bio-Technology and Solarbio (Beijing, China). 1-Ethyl-3-(3-(dimethylamino)propyl) carbodiimide (EDC) and n-hydroxysuccinimide (NHS) were purchased from Sigma (USA). Antibodies were purchased from Abcam.

Mouse forestomach carcinoma cell line (MFC), and murine macrophage cell line RAW 264.7 were purchased from the cell bank of Chinese Academy of Sciences (Shanghai, China).

\section{Animal}

Female Balb/c and ICR mice weighing 18-22 g were purchased from Qinglongshan Animal Breeding Farm (Nanjing, China). All animal studies were approved by the Laboratory Animal Management Committee of Jilin University and performed in compliance with the ethical principles of the Experimental Animal Welfare Ethics Committee of Jilin University. 


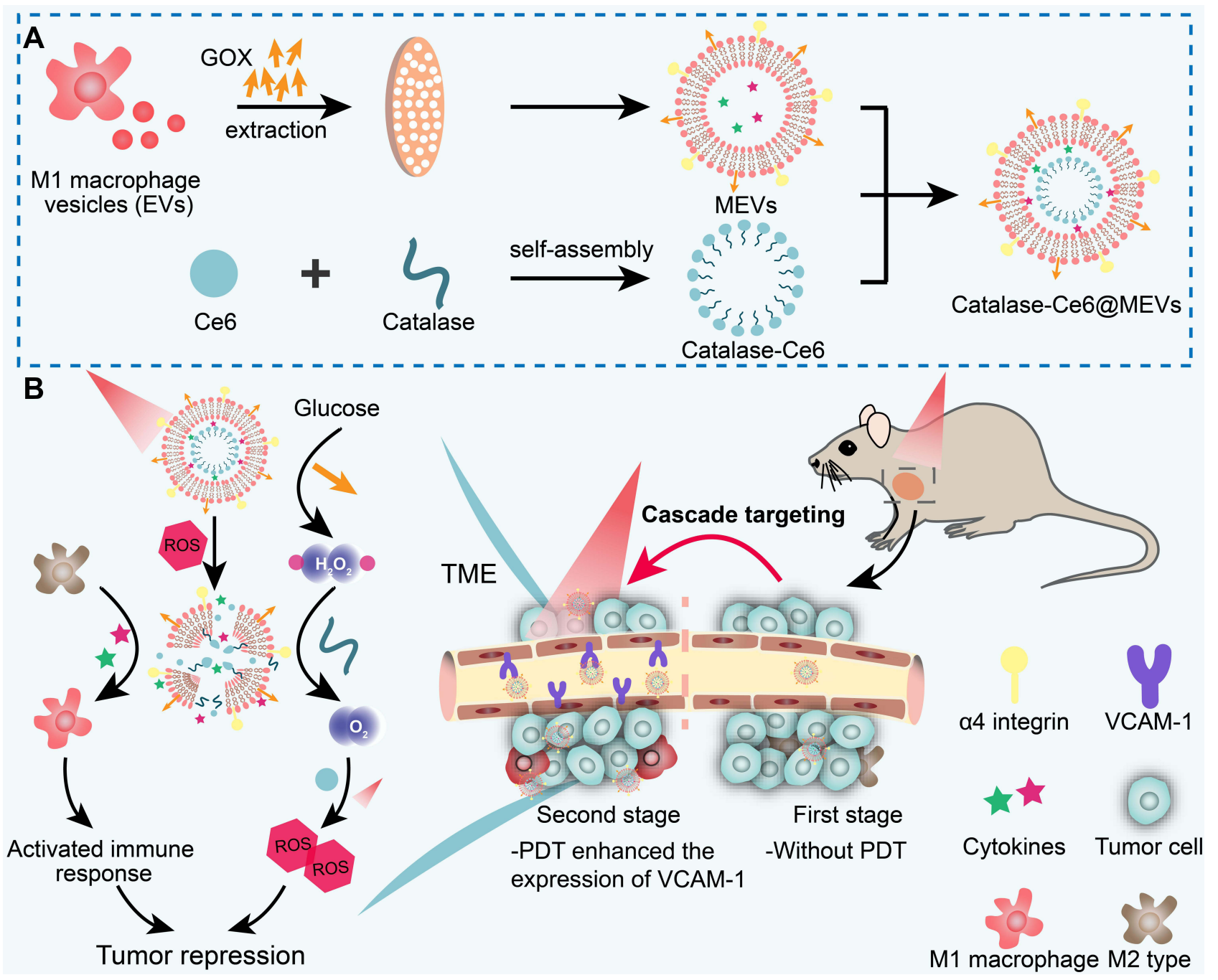

Scheme I The schematic diagram of fabrication process (A) and treatment principle (B) of Catalase-Ce6@MEVs.

\section{Synthesis of Catalase-Ce6}

Catalase-Ce6 was synthesized as previously described. ${ }^{36}$ In brief, $0.64 \mathrm{mg}$ of EDC and $0.42 \mathrm{mg}$ of NHS were added into $0.5 \mathrm{~mL} \mathrm{Ce} 6\left(20 \mathrm{mg} \mathrm{mL}^{-1}\right)$ solution and the mixture were stirred in the dark for $30 \mathrm{~min}$ at room temperature. Then $5 \mathrm{~mL}$ of catalase $\left(1 \mathrm{mg} \mathrm{mL}^{-1}\right)$ solution were added into the aforesaid mixture and stirred together overnight to obtain Catalase-Ce6. The preliminary product was subjected to dialysis in phosphate buffered solution (PBS) solution for $24 \mathrm{~h}$ to obtain pure Catalase-Ce6.

\section{Isolation of MI Macrophage Extracellular Vesicles (EVs) and Synthesis of Catalase-Ce6@MEVs}

RAW 264.7 cells were stimulated to differentiate into

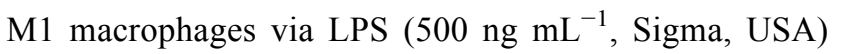

for $24 \mathrm{~h}$. To isolate EVs, M1 macrophages were cultured in serum-free DMEM medium for $48 \mathrm{~h}$ at $37^{\circ} \mathrm{C}$ in $5 \%$ $\mathrm{CO}_{2}$. Afterwards, cell conditional medium was collected and centrifuged at $2000 \mathrm{rpm}$ for $4 \mathrm{~min}$ to remove cell debris. Then the supernatant was concentrated using ultrafiltration device (10 kDa, Beyotime, Shanghai, China) under $2000 \mathrm{~g}$ for $20 \mathrm{~min}$ around 10 times. Finally, the product was extruded through 400, $200 \mathrm{~nm}$ polycarbonate films consecutively to obtained uniform EVs. ${ }^{37}$

GOX was inserted into EVs through extrusion $(\times 10)$ to form MEVs. Finally, Catalase-Ce6 and MEVs were coextruded through a $200 \mathrm{~nm}$ polycarbonate film 20 times to harvest Catalase-Ce6@MEVs.

Dynamic Light Scattering (DLS) (Litesizer 500, Anton Paar, Austria) was used to measure the size distributions and zeta potentials of Catalase-Ce6, MEVs and Catalase- 
Ce6@MEVs. Transmission electron microscope (TEM) (JEM-2000 EX II, JEOL Company, USA) was used to observe the morphology of different formulations. Ultraviolet spectrophotometer (UV-2550, SHIMADZU, Japan) was used to testify the uploading of different components. SDS-polyacrylamide gel electrophoresis (SDSPAGE) was used to analyze the protein compositions. In brief, different formulations were mixed with loading buffer (New Cell \& Molecular, Suzhou, China) and samples were boiled for $10 \mathrm{~min}$ to make protein denature. Then, samples were separated on Bis-Tris gel (Beyotime, Shanghai, China) and stained using coomassie blue staining solution for further analysis.

\section{Encapsulation Efficiency and Loading Rate of Catalase-Ce6@MEVs}

A series of Catalase-Ce6@MEVs with different concentrations of $\mathrm{Ce} 6$ were constructed and purified by dialysis method. $2 \mathrm{~mL}$ of different formulations were lyophilized for 2 days and demulsified using methanol under ultrasonic treatment, followed by measuring the concentration of Ce6 using fluorospectro photometer (Spectrofluorometer FS5, Edinburgh Instruments, UK). The encapsulation efficiency and loading rate of catalase and GOX was measured using the same method.

\section{Drug Release Rate of Catalase-Ce6@MEVs Under Laser Irradiation}

Drug release rate of Catalase-Ce6@MEVs was measured using dialysis method. $3 \mathrm{~mL}$ of Catalase-Ce6@MEVs dispersing in a dialysis bag (MWCO, $3.5 \mathrm{kDa}$ ) was immersed in $150 \mathrm{~mL}$ PBS under magnetic stirring. Laser irradiation $\left(660 \mathrm{~nm}, 0.08 \mathrm{~W} / \mathrm{cm}^{2}\right)$ was conducted to nanoparticles for $10 \mathrm{~min}$ or not. At predetermined time points, $1 \mathrm{~mL}$ of peripheral solution was taken out to measure the release of Catalase-Ce6 using fluorospectro photometer and equal volume PBS solution was added to ensure the accuracy of the measurement.

\section{Evaluation of the Catalytic Performance of MEVs}

The catalytic efficiency of MEVs was measured by calculating the generation of $\mathrm{H}_{2} \mathrm{O}_{2}$ with molybdic acid as the indicator. A series of MEVs (the concentration of GOX: 0 100 $\mu \mathrm{g} \mathrm{mL} \mathrm{m}^{-1}$ ) were prepared and incubated with $2 \mathrm{mM}$ glucose solution at $37^{\circ} \mathrm{C}$ for $2 \mathrm{~h}$ respectively. Then the concentration of $\mathrm{H}_{2} \mathrm{O}_{2}$ was measured by ultraviolet spectrophotometer at the absorbance of $405 \mathrm{~nm}$. Different concentrations of free GOX solution was served as positive control.

\section{Extracellular Measurement of $\mathrm{O}_{2}$ Concentration}

The reaction mixture (glucose $=2 \mathrm{mM}, \mathrm{H}_{2} \mathrm{O}_{2}=1 \mathrm{mM}$ ) was incubated with Ce6, Catalase-Ce6, Catalase-Ce6@EVs and Catalase-Ce6@MEVs (2 mL) for 15 min. Equal volume PBS solution served as a control group. Afterwards, a probe of the dissolved $\mathrm{O}_{2}$ meter was inserted under the surface of the solution to record the concentration of dissolved $\mathrm{O}_{2}$.

\section{Extracellular Measurement of ${ }^{\prime} \mathrm{O}_{2}$ Concentration}

The 1,3-diphenylisobenzonfuran (DPBF, Sigma-Aldrich) probe was applied to measure the ${ }^{1} \mathrm{O}_{2}$ generation. DPBF solution ( $10 \mu \mathrm{L}, 10 \mathrm{mM}$ in DMSO) was added to the $2 \mathrm{~mL}$ test solution (the ingredients were as described above) under laser irradiation $\left(660 \mathrm{~nm}, 0.08 \mathrm{~W} / \mathrm{cm}^{2}, 10 \mathrm{~min}\right)$. The absorbance of DPBF at $420 \mathrm{~nm}$ was recorded every minute.

\section{Cellular Uptake of Catalase-Ce6@MEVs}

MFC and RAW 264.7 cells $\left(3 \times 10^{5}\right)$ were cultured in the confocal dishes overnight. The next day, $25 \mu \mathrm{L}$ of free Ce6, Catalase-Ce6 or Catalase-Ce6@MEVs were added into the dishes respectively. Two h later, cells were rinsed twice with PBS and fixed using 4\% paraformaldehyde. Then cell nucleus was stained with DAPI (KeyGen BioTECH, Nanjing, China) for observation under confocal laser scanning microscopy (CLSM) (LSM800, Zeiss, Germany). The quantification data was analyzed by the software ImageJ.

\section{In vivo Bio-Distribution Assay}

The MFC-tumor bearing mice were injected intravenously with $100 \mu \mathrm{L}$ free Ce6, Catalase-Ce6 or Catalase-Ce6 @MEVs (with same concentration of Ce6) and imaged under IVIS Lumina System (IVIS Lumina XR, USA) at predetermined time points. After the last time point, tumor and five major organs (heart, liver, spleen, lung, kidney) of mice were dissected for ex vivo imaging.

In vivo blood circulations of different formulations were carried out by measured the signal intensity of Ce6 in the serum of mice. Free Ce6, Catalase-Ce6 and Catalase-Ce6@MEVs were administered intravenously to 
three groups of ICR mice $(n=3)$ respectively. At predetermined time points, $1 \mathrm{~mL}$ blood was collected, stood still for $1 \mathrm{~h}$ at $4^{\circ} \mathrm{C}$ and centrifuged under $4000 \mathrm{rpm}$ (10 min). The fluorescence of $\mathrm{Ce} 6$ in the supernatant was analyzed using fluorospectro photometer. The blood routine and biochemistry analyses were carried out by enzyme-linked immunosorbent assay (Elisa) following the product instruction.

The cascade targeting performance of Catalase-Ce6 @MEVs under PDT was investigated as follows. MFCtumor bearing mice were injected intravenously of Catalase-Ce6@MEVs and subjected to image at 4 h postinjection. Then mice were exposed to laser irradiation (660 $\mathrm{nm}, 0.08 \mathrm{~W} / \mathrm{cm}^{2}, 10 \mathrm{~min}$ ), followed by imaging at different predetermined time points.

\section{Cell Cytotoxicity}

MTT was used to investigate the cell viability after incubation with Ce6, Catalase-Ce6, Catalase-Ce6@EVs and Catalase-Ce6@MEVs with increasing Ce6 concentration $(n=6) .5 \times 10^{3}$ MFC cells were seeded into a 96-well plate per well overnight at $37^{\circ} \mathrm{C}$ in $5 \% \mathrm{CO}_{2}$. The next day, cells were incubated with different formulations and subjected to laser irradiation $\left(660 \mathrm{~nm}, 0.08 \mathrm{~W} / \mathrm{cm}^{2}, 10 \mathrm{~min}\right)$ or not after $4 \mathrm{~h}$. After incubation for another $4 \mathrm{~h}, 10 \mu \mathrm{L}$ of MTT (BioFroxx, Guangzhou, China) solution $\left(5.0 \mathrm{mg} \mathrm{mL}{ }^{-1}\right.$ PBS) was added to each well. At $4 \mathrm{~h}$ post-incubation, $150 \mu \mathrm{L}$ of DMSO replaced culture medium and the 96well plate was under shaking for $15 \mathrm{~min}$, followed by measuring the absorbance at $490 \mathrm{~nm}$ using microplate reader.

For cell apoptosis assay, $3 \times 10^{5} \mathrm{MFC}$ cells were seeded into a 6-well plate overnight. The next day, cells were incubated with different formulations (Ce6 concentration was $\left.6 \mu \mathrm{g} \mathrm{mL}^{-1}\right)$ and subjected to laser irradiation (660 nm, $0.08 \mathrm{~W} / \mathrm{cm}^{2}, 10 \mathrm{~min}$ ) after $4 \mathrm{~h}$. After another $4 \mathrm{~h}$, cells were harvested and measured by AV-PI apoptosis detection kit (AM-PI detection kit) using flow cytometry (FCM, $\mathrm{BD}$, America) (CLSM) according to product instructions.

\section{In vivo Anti-Tumor Assay}

The MFC-tumor bearing mice were inoculated as follows. Every female Balb/c mouse was subcutaneous injection of $5 \times 10^{6}$ MFC cells $(100 \mu \mathrm{L})$ into the right axilla. When the tumor volume reached $70 \mathrm{~mm}^{3}$, mice were randomly divided into five groups $(n=5)$ and intravenously injected with different formulations: (1) PBS; (2) Ce6; (3) Catalase-Ce6; (4) Catalase-Ce6@EVs; (5) Catalase-Ce6
@ MEVs every two days (Ce6 concentration: 6 $\left.\mu \mathrm{g} \mathrm{mL}{ }^{-1}\right)$. Then laser irradiation $\left(660 \mathrm{~nm}, 0.08 \mathrm{~W} / \mathrm{cm}^{2}\right.$, $10 \mathrm{~min}$ ) was carried out after $8 \mathrm{~h}$ of injection. Body weight and tumor volume were recorded along with the treatment cycle. After five treatments, mice were dissected and tumors were collected for immunofluorescence and H\&E staining to investigate the curative effect and M2 macrophages repolarization function of different formulations. Five main organs were dissected for $H \& E$ staining to investigate the systemic toxicity.

\section{Results}

\section{Construction and Characterization of Catalase-Ce6@MEVs}

Here, hydrophilic catalase and lipophilic Ce6 formed selfassembled nanocomplex (Catalase-Ce6) through covalent bonds and hydrophobic interactions. GOX-modified M1 macrophage extracellular vesicles (MEVs) were harvested through coextrusion and further co-extruded with Catalase-Ce6 to obtain Catalase-Ce6@MEVs. CatalaseCe6 showed uniform size and good dispersion in the PBS solution and Catalase-Ce6@MEVs displayed obvious bilayer structure (Figure 1A). The average particle sizes of Catalase-Ce6, MEVs and Catalase-Ce6@MEVs were $74.99,142.15$ and $166.59 \mathrm{~nm}$ respectively (Figure 1B). The zeta potentials of them presented a downward tendency, indicating the upload of each component (Figure 1C). Successful synthesis of Catalase-Ce6 (a) MEVs was further authenticated through UV-vis spectrum. As shown in Figure 1D, Catalase-Ce6@MEVs exhibited the characteristic peaks of $\mathrm{Ce} 6$, catalase and GOX, which confirmed the successful loading of them into nanoparticles. The result of SDS-PAGE was coincidence with above-mentioned results (Figure 1E). Finally, we found that the ability of Catalase-Ce6 to hydrolyze $\mathrm{H}_{2} \mathrm{O}_{2}$ was equal to pure catalase, which validated that Catalase-Ce6 maintained enzymatic activity (Figure 1F). These results implied the successful fabrication of Catalase-Ce6@MEVs without impairing the functionality of catalase.

\section{The Properties of Catalase-Ce6@MEVs}

Primarily, the stability of Catalase-Ce6@MEVs in different solution environments was studied. Figure $2 \mathrm{~A}$ showed that Catalase-Ce6@MEVs maintained consistent particle size no matter in PBS or fatal bovine serum (FBS) solution over 7 days, demonstrating their distinguished stability, which 

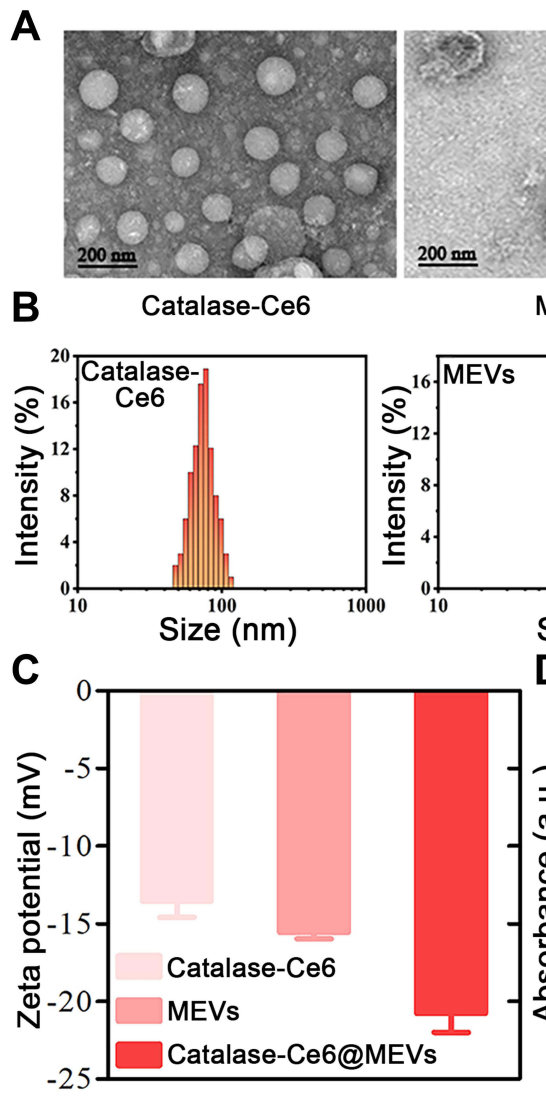

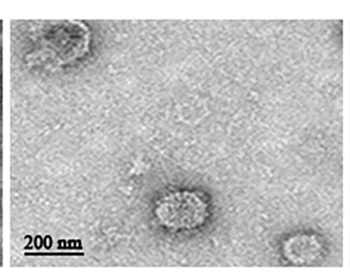

MEVs

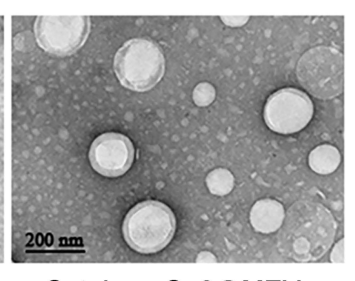

Catalase-Ce6@MEVs
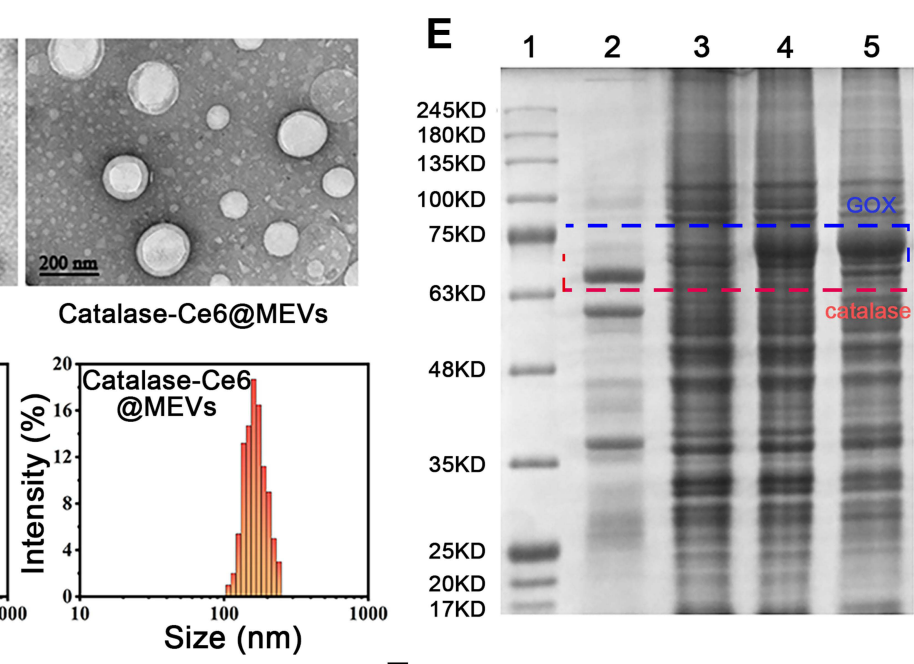

D

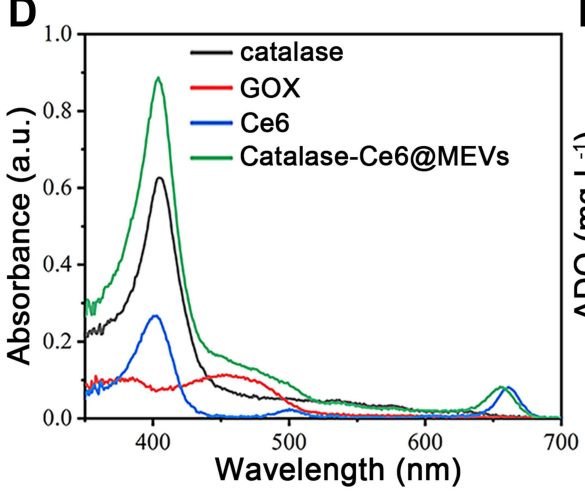

$\mathbf{F}$

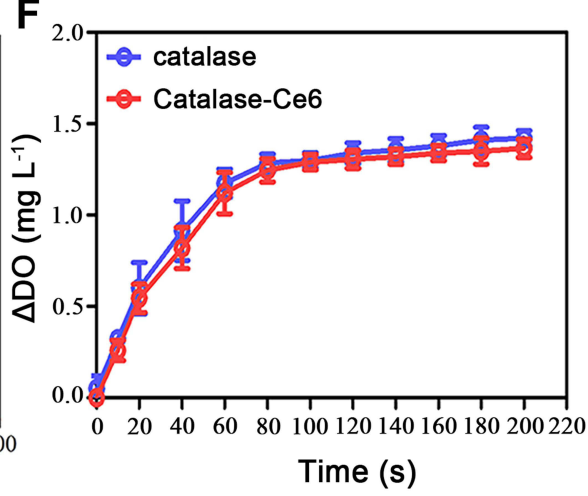

Figure I Synthesis and characterization of Catalase-Ce6@MEVs. (A) Transmission electron microscope (TEM) image of Catalase-Ce6, MEVs and Catalase-Ce6@MEVs. Scan bar, $200 \mathrm{~nm}$. Particle size distributions (B) and Zeta potentials (C) of different formulations. (D) UV-vis spectra of catalase, GOX, Ce6 and Catalase-Ce6@MEVs. (E) SDS-PAGE pattern of proteins from (I) marker, (2) catalase, (3) EVs, (4) MEVs and (5) Catalase-Ce6@MEVs. The blue and red dotted lines indicated GOX and catalase respectively. $(\mathbf{F}) \mathrm{O}_{2}$ concentration detection over time when catalase or Catalase-Ce6 was incubated with $\mathrm{H}_{2} \mathrm{O}_{2}$ solution $\left(\mathrm{H}_{2} \mathrm{O}_{2}=\mathrm{I} \mathrm{mM}\right.$, catalase $=0.3 \mathrm{mg} \mathrm{mL}^{-1}$ ).

made them suitable for use in vivo. Meanwhile, the percentage of released Catalase-Ce 6 was under $10 \%$ but shot up to 84.3\% upon laser irradiation for $10 \mathrm{~min}$, revealing that PDT favored the crack of nanoparticles and release of CatalaseCe6 (Figure 2B). To investigate whether the catalytic performance of GOX was affected after inserting into EVs, pure GOX or MEVs were incubated with glucose solution (2 $\mathrm{mM}$ ) for $2 \mathrm{~h}$. The results suggested that the activity of GOX in MEVs was comparable to pure GOX, degrading glucose in an efficient manner (Figure 2C). The encapsulation efficiency and loading rate were $32 \%$ and $20.35 \%$ for GOX (Figure 2D), 53.5\% and 33.9\% for Ce6 (Figure 2E), and $50.15 \%, 29.4 \%$ for catalase (Figure $2 \mathrm{~F}$ ) respectively. Then, the cascade catalytic effect between GOX and catalase of Catalase-Ce6@MEVs was explored extracellularly. Although the $\mathrm{O}_{2}$ generation of Catalase-Ce6 and CatalaseCe6@EVs groups showed a gradual increase in the first few minutes, Catalase-Ce6@MEVs groups produced nearly twice as much dissolved $\mathrm{O}_{2}$ as the formers. It is worth noting that the high dissolved $\mathrm{O}_{2}$ production owns to the cascade oxidation performance by consuming glucose to produce $\mathrm{H}_{2} \mathrm{O}_{2}$ with $\mathrm{GOX}$ and decomposing $\mathrm{H}_{2} \mathrm{O}_{2}$ into $\mathrm{O}_{2}$ with catalase. Conversely, the PBS and $\mathrm{Ce} 6$ group showed negligible changes within the test period (Figure 2G). 1.3-diphenylisobenzofuran (DPBF) was further used to measure the generation of ${ }^{1} \mathrm{O}_{2}$. As showed in Figure $2 \mathrm{H}$, the DPBF content of Catalase-Ce6@MEVs displayed significant decline compared with the PBS group under the irradiation of $660 \mathrm{~nm}$ laser. These results suggested the superiority of the combination of GOX and catalase over single component, corroborating the remarkable synergistic effect of Catalase-Ce6@MEVs collaborating with PDT.

Lastly, the cellular uptake ability was studied using CLSM. As exhibited in Figure 2I, Catalase-Ce6@MEVs displayed pronounced endocytosis by MFC cells compared to $\mathrm{Ce} 6$ and Catalase-Ce6 groups. It was worth noting that lower cellular capture of Catalase-Ce6@MEVs was observed in RAW cells, indicating that EVs providing 


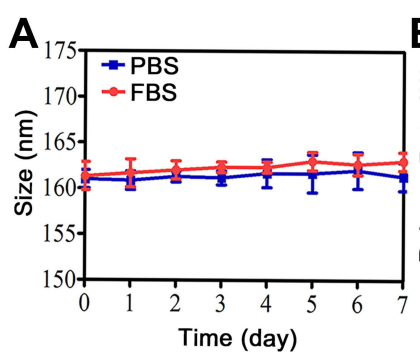

E

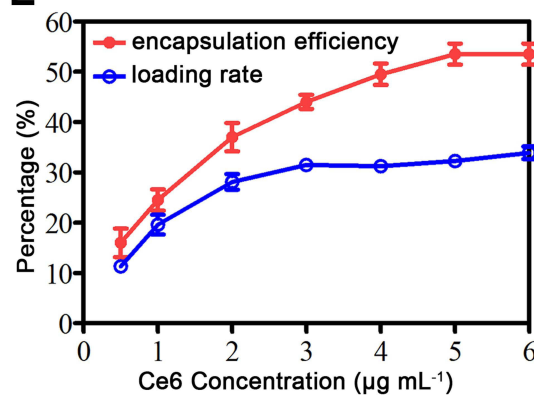

G

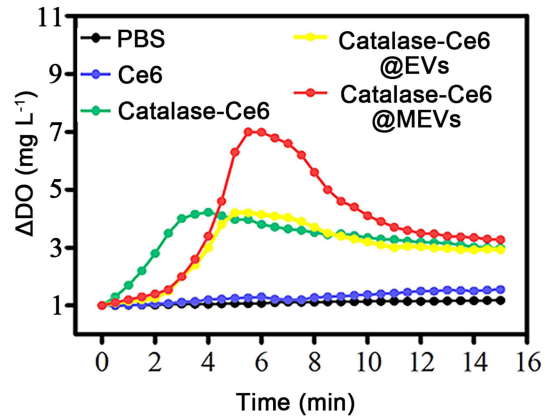

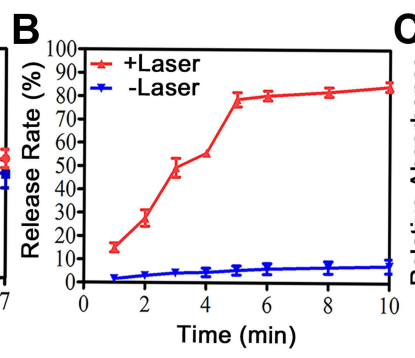

$\mathbf{F}$

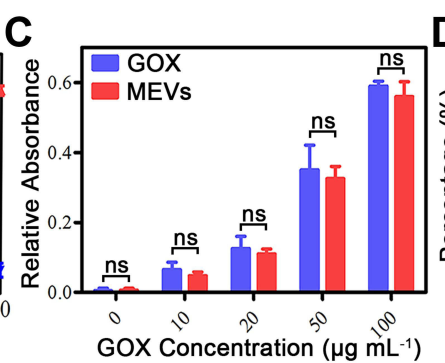

I
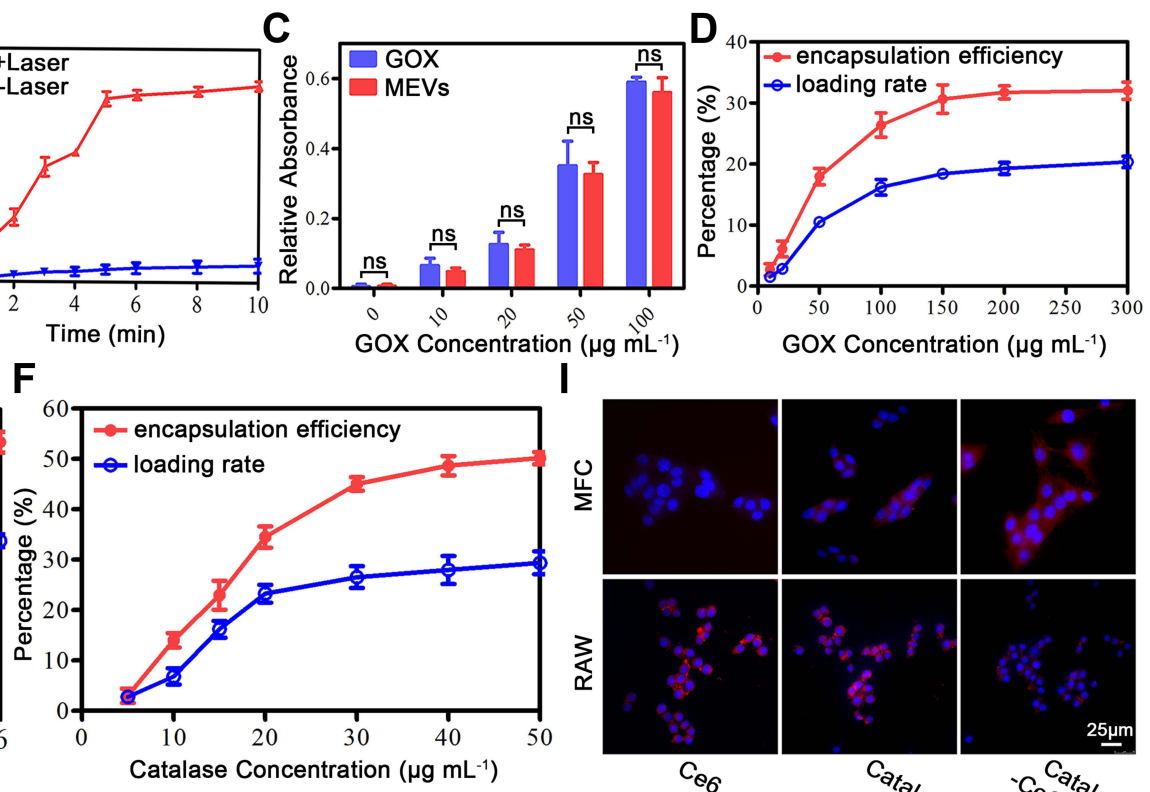

H

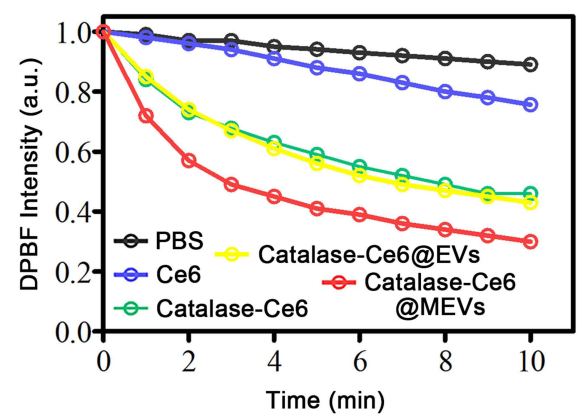

$c_{e_{6}}$

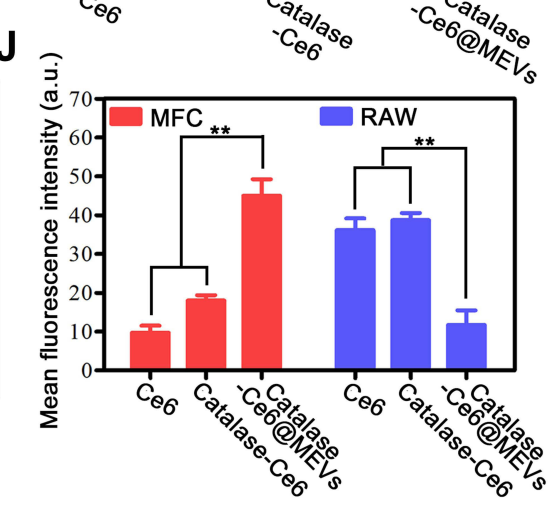

Figure 2 In vitro performances of Catalase-Ce6@MEVs. (A) The stability of Catalase-Ce6@MEVs in PBS or FBS during 7 days. (B) The rate of released Catalase-Ce6 of Catalase-Ce6@MEVs under laser irradiation $\left(660 \mathrm{~nm}, 0.08 \mathrm{~W} / \mathrm{cm}^{2}, 10 \mathrm{~min}\right)$ or not. (C) The glucose catalytic activity of pure GOX and MEVs with increasing concentration of GOX (glucose $=2 \mathrm{mM}$ ). The encapsulation efficiency and loading rate of GOX (D), Ce6 (E) and catalase (F). (G) $\mathrm{O}_{2}$ concentration detection over time when different formulations were incubated with reaction mixture (glucose $=2 \mathrm{mM}, \mathrm{H}_{2} \mathrm{O}_{2}=1 \mathrm{mM}$ ). (H) Time-dependent degradation of DPBF when incubating with different formulations under laser irradiation. (I) Cellular uptake of Ce6, Catalase-Ce6 or Catalase-Ce6@MEVs. Scan bar, $25 \mu$ m. (J) The quantification analyses of the cellular uptake of Ce6, Catalase-Ce6 and Catalase-Ce6@MEVs. Data are presented as mean \pm SD, statistical significance of (C and J) were analyzed via T-test with two-tails and one-way ANOVA respectively. ns $=P \geq 0.05$, $* * P<0.01$.

a decent camouflage effect. The quantitative data was consistent with aforementioned phenomena (Figure 2J). These results demonstrated that Catalase-Ce6@MEVs was a practical nanoplatform for anti-tumor therapy.

\section{In vivo Bio-Distribution of Catalase-Ce6@MEVs}

In this section, bio-distribution of Catalase-Ce6@MEVs was evaluated firstly. MFC-tumor bearing mice were injected intravenously with free $\mathrm{Ce} 6$, Catalase-Ce6 or Catalase-Ce6@MEVs respectively. In comparison with free Ce6, Catalase-Ce6@MEVs started to target tumor tissue $2 \mathrm{~h}$ after the injection and the accumulation reached the peak at $8 \mathrm{~h}$ post-injection. Moreover, the signal of $\mathrm{Ce} 6$ was still visible at $24 \mathrm{~h}$ post-injection. Nevertheless,
Catalase-Ce6 showed the tendency of tumor-targeting later and displayed weaker fluorescence signal in tumor section (Figure 3A). After the last time point, tumor, heart, liver, spleen, lung and kidney were subjected to in vitro imaging and immunofluorescent staining (IF) to detect the tumor infiltration of different formulations (Figure 3B and C), the results of which were consistent with in vivo imaging. Figure 3D revealed that Catalase-Ce6@MEVs presented longer circulating time than Catalase-Ce6 and free Ce6 in the blood. These results indicated that EVs enhanced the biocompatibility and tumor targeting ability of Catalase-Ce6@MEVs. Meanwhile blood routine and biochemistry analyses of the mice injected of different formulations validated the safety of nanoparticles without laser irradiation (Figure 3E). 

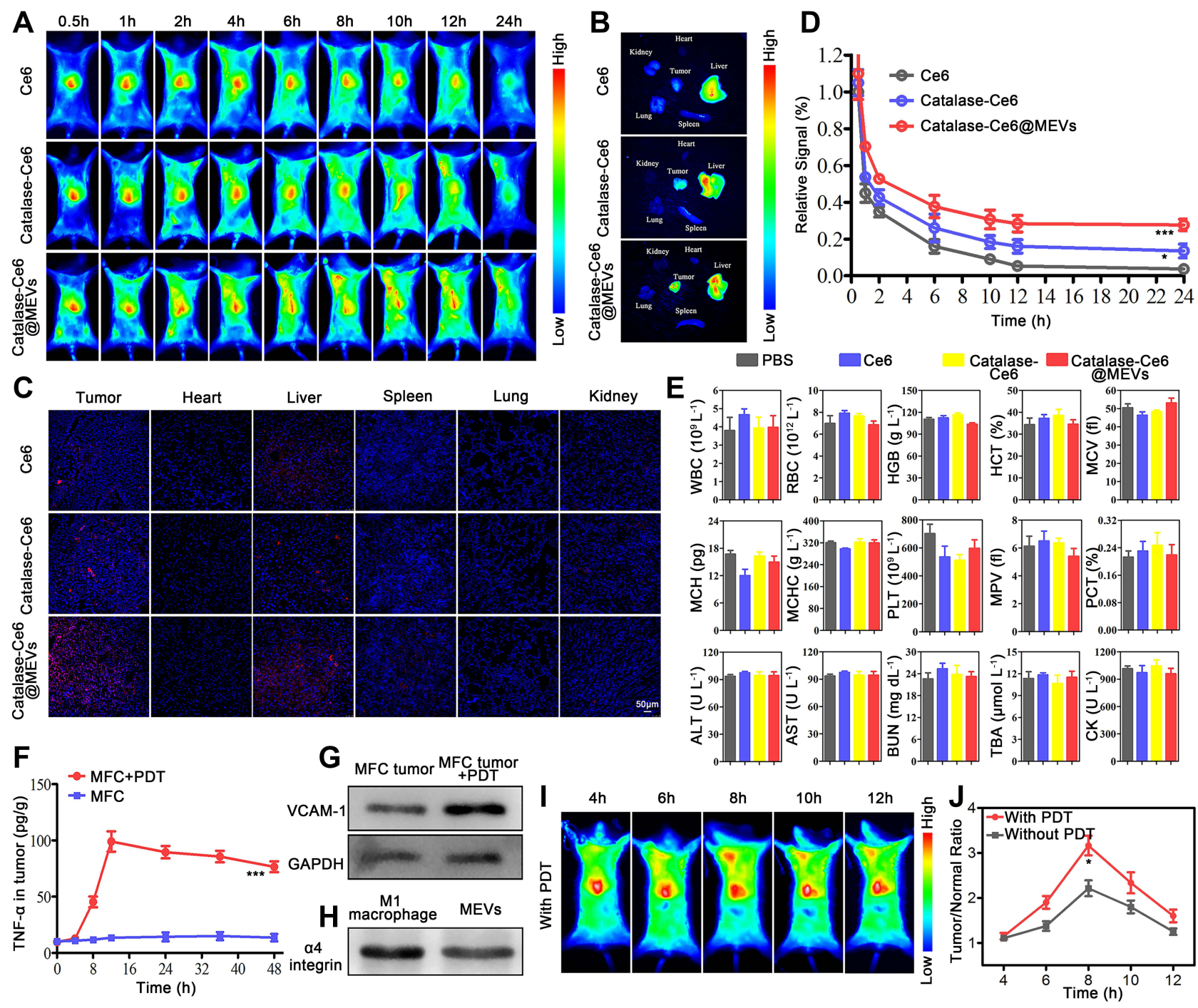

Figure 3 In vivo bio-distribution and safety evaluation of Catalase-Ce6@MEVs. (A) In vivo tumor targeting ability of Ce6, Catalase-Ce6 or Catalase-Ce6@MEVs over time. (B) Ex vivo imaging of tumors and five organs at $24 \mathrm{~h}$ post-injection. (C) Tumors and organs infiltrations of different formulations at $24 \mathrm{~h}$ post-injection. Scan bar, $50 \mu \mathrm{m}$. (D) Fluorescence signal of $\mathrm{Ce} 6$ in the serum over time after mice injected with different formulations. (E) Blood routine and biochemistry analyses of the mice injected with different formulations after 48 h. (F) The concentration of TNF- $\alpha$ in tumor over time of MFC-tumor bearing mice that were injected with Catalase-Ce6@MEVs under PDT or not. (G) Changes in VCAM-I expression in tumor after MFC-tumor bearing mice that were subjected with PDT treatment. (H) The expression of $\alpha 4$ integrin in MI macrophage and MEVs. (I) Cascade tumor targeting ability of Catalase-Ce6@MEVs to subcutaneous MFC-tumor bearing mice undergone PDT treatment. (J) The Tumor/ Normal ratio of fluorescence signal of the mice undergone PDT treatment or not. Data derived from the last group of (A and I). PDT: $660 \mathrm{~nm}, 0.08 \mathrm{~W} / \mathrm{cm}{ }^{2}$, I0 min. Data are presented as mean $\pm S D$, statistical significance of $(\mathbf{D})$ and $(\mathbf{F}$ and $\mathbf{J})$ were analyzed via one-way ANOVA and $T$-test with two-tails respectively. $* P<0.05$, $* * * P<0.001$.

It is reported that macrophages can be recruited to the tissues of high VCAM-1 expression, by virtue of membrane protein $\alpha 4$ integrin. Meanwhile, the expression of VCAM-1 can be stimulated by some inflammatory factors, such as tumor necrosis factor- $\alpha$ (TNF- $\alpha$ ). We firstly explored whether PDT would promote the expression of TNF- $\alpha$ in tumor tissues of the subcutaneous MFC-tumor bearing mice. As displayed in Figure 3F, compared to negligible change in the group without PDT, the concentration of TNF- $\alpha$ in tumor section conspicuously increased under the treatment of PDT and maintained high level for a long time. Western blot analysis demonstrated that local inflammation induced by PDT increased the expression of VCAM-1 in MFC tumor tissue (Figure 3G). What's more, we found the expression of $\alpha 4$ integrin on EVs and catalase-Ce6@MEVs, which indicated that isolation and modification of EVs did not lose their intrinsic components (Figure $3 \mathrm{H}$ ). Considering that PDT can also increase vascular permeability, it may promote tumor accumulation of Catalase-Ce6@MEVs to a large extent, realizing cascade targeting effect. To verify the inference, MFC-tumor bearing mice were injected with Catalase-Ce6@MEVs and imaged for the first time at 4 $\mathrm{h}$ post-injection. Then mice were subjected to laser irradiation for $10 \mathrm{~min}$, followed by imaged at predetermined time 
points. The in vivo imaging and quantification analysis of fluorescence signal showed that PDT significantly elevated the tumor targeting ability of Catalase-Ce6@MEVs. These results illustrated the outstanding tumor targeting capacity of Catalase-Ce6@MEVs under PDT. It is worth noting that the ingenious cascade tumor targeting should be ascribed to the synergistic effects: the up-regulation of targeted ligand VCAM-1 and enhanced vascular permeability.

\section{In vitro Cell Cytotoxicity of Catalase-Ce6@MEVs Combining with PDT}

On the basis of aforementioned results, we studied the cell cytotoxicity of Catalase-Ce6@MEVs next. More than 80\% of MFC cells were viable when cells were incubated with different formulations at a concentration of $\mathrm{Ce} 6$ as high as $6 \mu \mathrm{g} \mathrm{mL}^{-1}$ without laser irradiation (Figure 4A). On the contrary, once laser irradiation was added, varying degrees of cell death were appeared in all experiment groups and Catalase-Ce6@MEVs caused the highest mortality (Figure 4B). It should be noted that the higher cytotoxicity for Catalase-Ce6@MEVs as compared with other groups was resulted from the promoted cellular uptake of Catalase-Ce6@MEVs with the assistance of EVs and the enhanced generation of ROS ascribing to the combination of GOX, catalase and PDT (Figure 4C). The calcein-AM and propidium iodide (AM-PI) double-staining was used to further assess the cell killing efficiency of Catalase-Ce6 @MEVs combining with laser irradiation. As shown in Figure 4D, a great deal of red fluorescence was observed in Catalase-Ce6@MEVs, revealing adequate PDT efficiency as opposed to weaker red fluorescence signals of other groups. Furthermore, the result of Annexin V-FITC and PI (AV-PI) staining was concordant with the above experiments (Figure 4E). These results suggested that Catalase-Ce6@MEVs combining with PDT could result in high mortality to MFC cells.
A

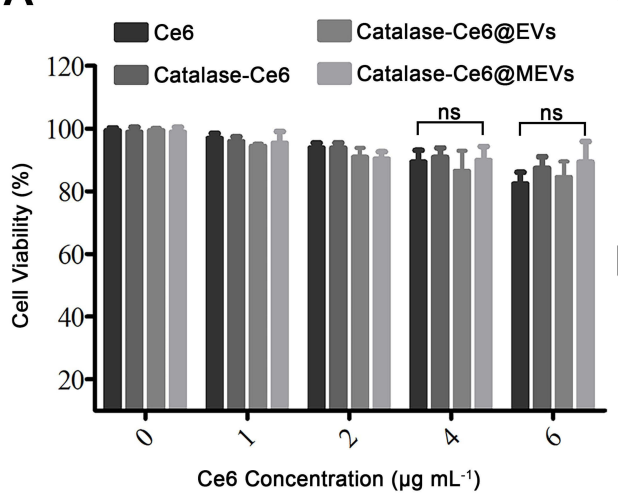

B

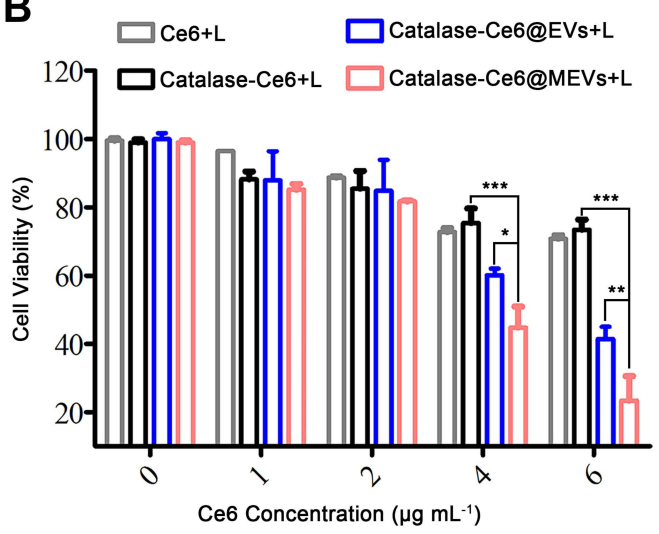

C PBS

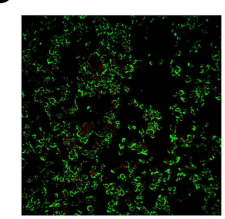

D

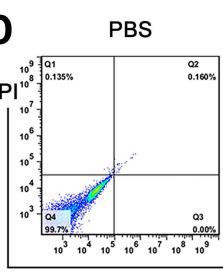

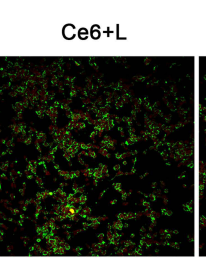
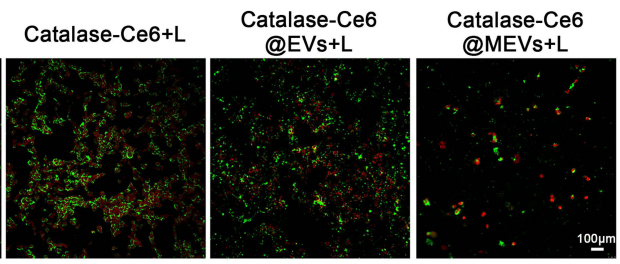

Catalase-Ce6

Ce6+L

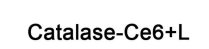
@EVs+L

Catalase-Ce6

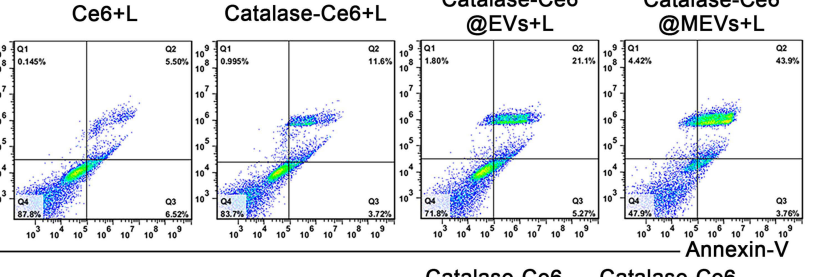

E

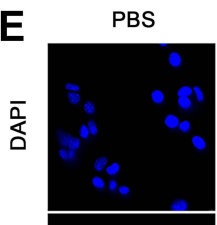

Ce6+L

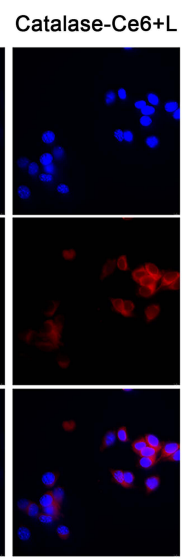
Catalase-Ce6 $\begin{array}{cc}\begin{array}{c}\text { Catalase-Ce6 } \\ @ E V s+L\end{array} & \begin{array}{c}\text { Catalase-Ce } \\ @ M E V s+L\end{array}\end{array}$
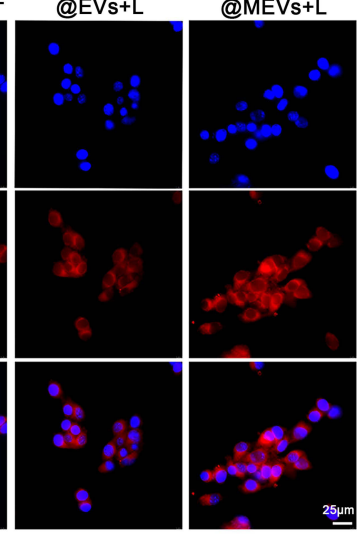

Figure 4 Cell cytotoxicity of Catalase-Ce6@MEVs. (A) Cell viability of MFC cells after incubation with different formulations without laser irradiation. (B) Cell viability of MFC cells after incubation with different formulations followed by laser irradiation for $10 \mathrm{~min}$. (C) The AM-PI double staining of MFC cells after incubation with different formulations followed by PDT treatment. The live cells were stained with calcein-AM (green) and dead cells were stained with propidium iodide (red). Scan bar, I00 $\mu \mathrm{m}$. (D) The cell apoptosis of MFC cells after incubation with different formulations followed by PDT treatment assessed with AV-PI. (E) IF analysis of ROS level (DCFH-DA, red fluorescence) in MFC cells after incubation with different formulations followed by PDT treatment. Scan bar, $25 \mu \mathrm{m}$. Data are presented as mean \pm SD, statistical significance was analyzed via one-way ANOVA. $n s=P \geq 0.05$, $* P<0.05$, $* * P<0.01$, $* * * P<0.00 \mathrm{I}$. 

A $\cdots$
Day
Subcutaneous tumor implantation
B
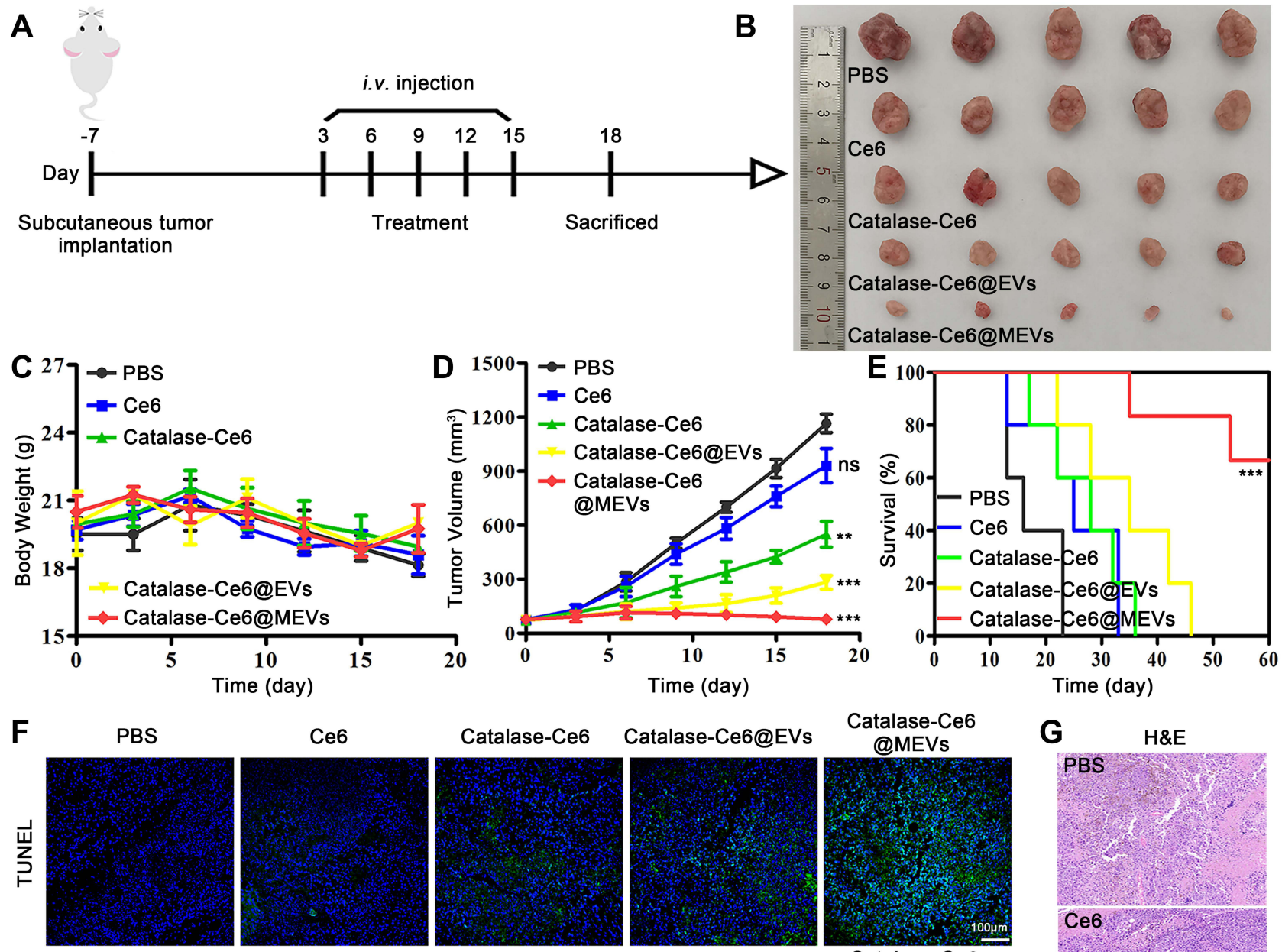

H

PBS

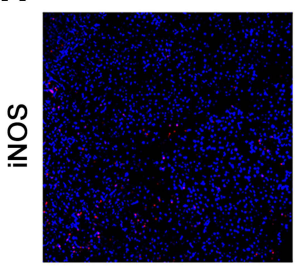

Ce6

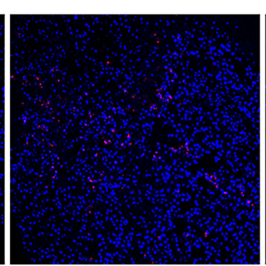

Catalase-Ce6
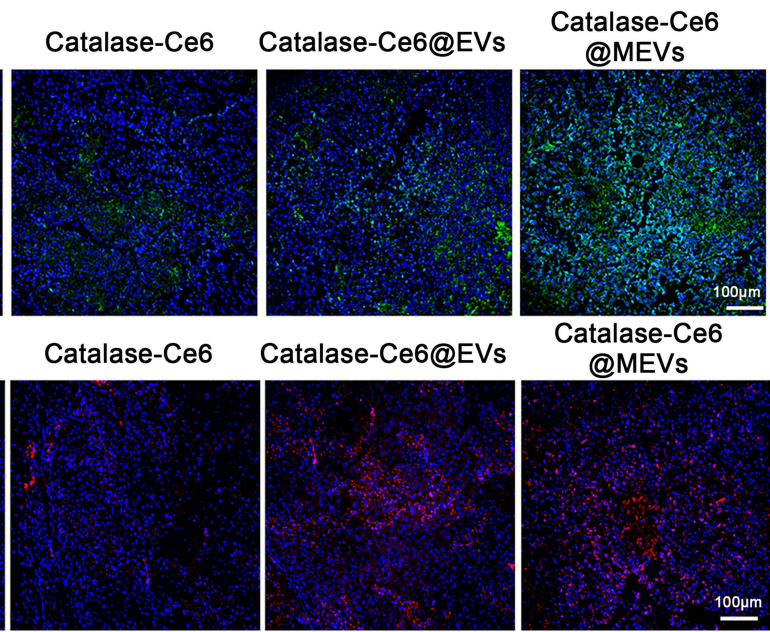

Catalase-Ce6 @MEVs
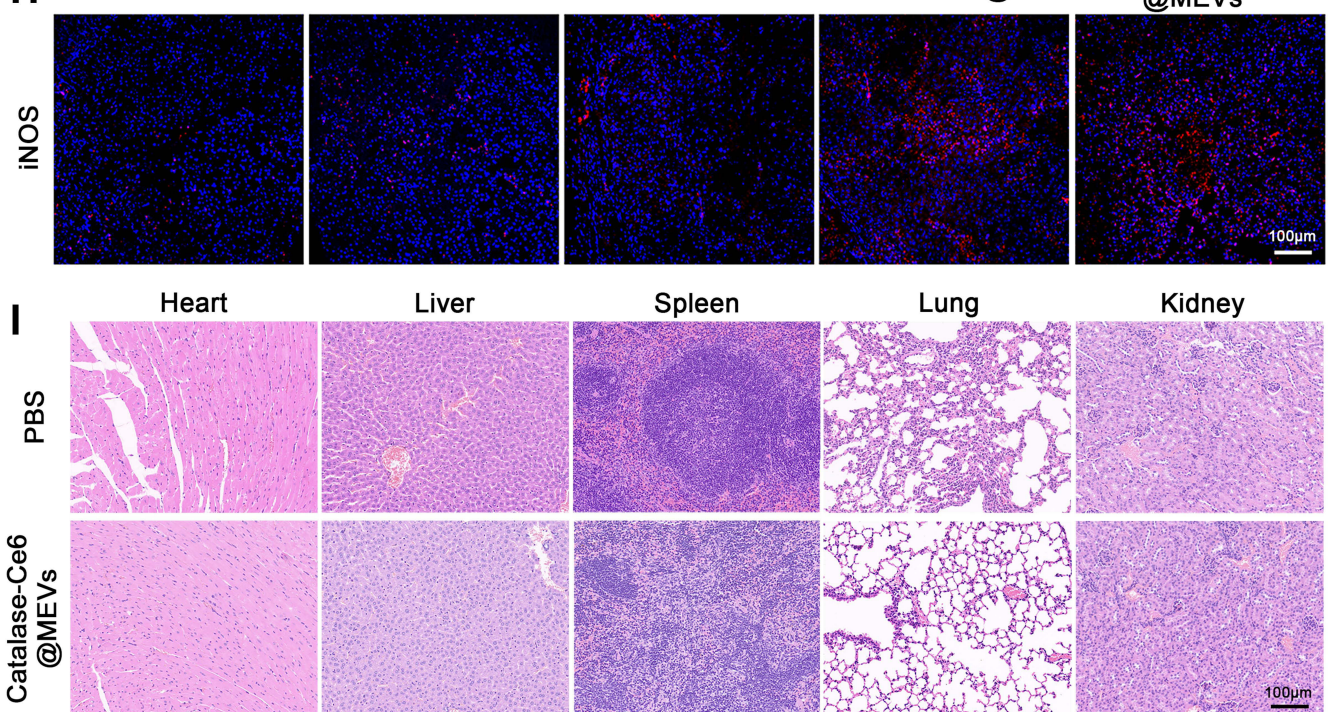

Liver
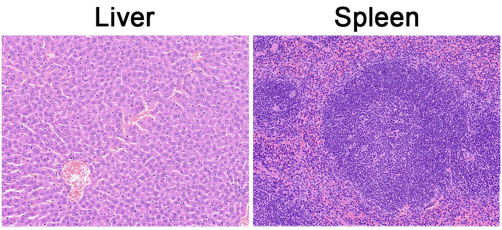

Lung

Kidney

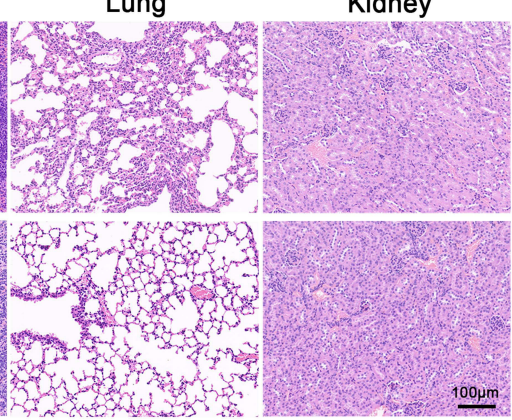

G
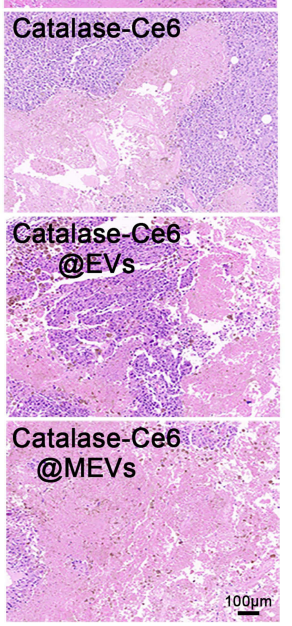

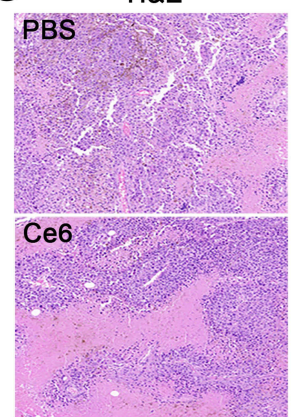

Figure 5 In vivo anti-tumor performance of Catalase-Ce6@MEVs uniting with PDT. (A) Therapeutic timer shaft for subcutaneous MFC tumor model. (B) Photographic images of tumors excised from mice treated with different formulations. (C) Changes in the body weight of the mice treated with different formulations. (D) The growth curves of tumor volume of the mice treated with different formulations. (E) The survival curves of the mice treated with different formulations. TUNEL (F) and H\&E (G) staining of tumors excised from mice treated with different formulations after the last treatment. Scan bar, $100 \mu \mathrm{m}$. (H) IF images for iNOS of tumor tissues from different groups at the $24 \mathrm{~h}$ after the last treatment. Scan bar, $100 \mu \mathrm{m}$. (I) H\&E staining of five organs of the mice treated with PBS and Catalase-Ce6@MEVs after the last treatment. Scan bar, $100 \mu \mathrm{m}$. Data are presented as mean \pm SD, statistical significance of (D) was analyzed by one-way ANOVA (compared with PBS group), and survival statistical significance was analyzed by log-rank (Mantel-Cox) test. ns $=P \geq 0.05, * * P<0.01$, $* * * P<0.001$. 


\section{Anti-Tumor Effects of PDT Induced by Catalase-Ce6@MEVs in the Subcutaneous MFC Tumor Model}

After confirming the palpable tumor targeting ability in vivo and cell lethality in vitro of Catalase-Ce6@MEVs, we subsequently evaluated the in vivo therapeutic effect of them using subcutaneous MFC-tumor model. The tumor model was established according to Figure 5A. When tumor volume reached $70 \mathrm{~mm}^{3}$, mice were randomly distributed into 5 groups and injected intravenously of different formulations, followed by laser irradiation. Body weight and tumor volume were recorded along with the therapy cycle. As shown in Figure 5C, the body weights of five groups did not appear significant changes comparing with their initial body weights during the whole period. Catalase-Ce6@MEVs group showed an obvious tumor suppression effect throughout the treatment cycle as opposed to uncontrolled increase in tumor volume of other groups (Figure 5D). The survival curves also revealed Catalase-Ce6@MEVs could prolong the survival time of mice (Figure 5E). At day 18, mice were sacrificed and tumor tissues were collected for further analysis. TUNEL staining assay for tumor slices displayed that Catalase-Ce6@MEVs contained more green fluorescence, which implied their excellent initiating cell apoptosis (Figure 5F). Furthermore, hematoxylin and eosin (H\&E) staining was correspond to the above results. Tumor tissues of the mice receiving administration of Catalase-Ce6@MEVs had fewer lesions (Figure 5G). To explore whether Catalase-Ce6@MEVs could repolarize M2 macrophage to M1 type, IF staining against inducible nitric oxide synthase (iNOS) of tumor tissues was used to detect the proportion of M1 macrophages. As demonstrated in Figure 5H, Catalase-Ce6@EVs and Catalase-Ce6@MEVs presented more red fluorescence signal, implying a higher percent of M1 macrophages, which meant the carrier of EVs or MEVs possessed the ability of M2 reeducation. Meanwhile, H\&E staining of five organs revealed that there was little difference in the pathological changes between PBS and Catalase-Ce6@MEVs groups, displaying the safety of Catalase-Ce6@MEVs in vivo (Figure 5I). All above results testified the prominent tumor repression effect, obvious M2 reprogram capacity along with high safety of Catalase-Ce6 @MEVs.

\section{Conclusion}

In summary, the amphiphilic nanocomplex Catalase-Ce6 could effectively solve the insoluble problem of $\mathrm{Ce} 6$, and the modification of Ce6 does not affect the catalytic activity of catalase. At the same time, the combination of catalase and GOX also achieved the purpose of cascade $\mathrm{O}_{2}$ supplementation, which effectively enhanced the ratio of ROS from PDT. Furthermore, macrophage vesicles were utilized to load the nanocomplex for the enhancement of tumor targeting ability. And due to the effect of PDT, a cascade tumor targeting effect was produced which allowed more drug accumulating into the tumor sites. In vitro and in vivo experiments also have shown that this therapeutic strategy could effectively increase the $\mathrm{O}_{2}$ content of tumor site, thus improving the efficacy of PDT.

\section{Acknowledgments}

This work was financially supported by the Health Special Project of Jilin Province (2018SCZ019) and Health Research Talent Special Project of Jilin Province (2019SCZ026).

\section{Disclosure}

The authors report no conflicts of interest in this work.

\section{References}

1. Xu J, Xu L, Wang C, et al. Near-Infrared-triggered photodynamic therapy with multitasking upconversion nanoparticles in combination with checkpoint blockade for immunotherapy of colorectal cancer. ACS Nano. 2017;11(5):4463-4474. doi:10.1021/acsnano.7b00715

2. Chen H, Tian J, He W, Guo Z. H 2 O 2 -Activatable and O 2 Evolving Nanoparticles for Highly Efficient and Selective Photodynamic Therapy against Hypoxic Tumor Cells. J Am Chem Soc. 2015;137(4):1539-1547. doi:10.1021/ja511420n

3. Zhao J, Fei J, Du C, Cui W, Ma H, Li J. Assembly of catalase-based bioconjugates for enhanced anticancer efficiency of photodynamic therapy in vitro. Chem Commun. 2013;49(91):10733. doi:10.1039/ c3cc46969g

4. Chang C-H, Qiu J, O'Sullivan D, et al. Metabolic Competition in the tumor microenvironment is a driver of cancer progression. Cell. 2015;162(6):1229-1241. doi:10.1016/j.cell.2015.08.016

5. Wu X, Yang H, Chen X, et al. Nano-herb medicine and PDT induced synergistic immunotherapy for colon cancer treatment. Biomaterials. 2021;269:120654. doi:10.1016/j.biomaterials.2021.120654

6. Jing $\mathrm{X}, \mathrm{Zhi} Z, \quad$ Zhang $\mathrm{N}$, et al. Multistage tumor microenvironment-responsive theranostic nanopeanuts: toward multimode imaging guided chemo-photodynamic therapy. Chem Eng J. 2020;385:123893. doi:10.1016/j.cej.2019.123893

7. Phua SZF, Yang G, Lim WQ, et al. Catalase-integrated hyaluronic acid as nanocarriers for enhanced photodynamic therapy in solid tumor. $A C S$ Nano. 2019;13(4):4742-4751. doi:10.1021/acsnano.9b01087

8. Cheng X, He L, Xu J, et al. Oxygen-producing catalase-based prodrug nanoparticles overcoming resistance in hypoxia-mediated chemo-photodynamic therapy. Acta Biomaterialia. 2020;112:234-249. doi:10.1016/j.actbio.2020.05.035

9. Zhu T, Shi L, Ma C, et al. Fluorinated chitosan-mediated intracellular catalase delivery for enhanced photodynamic therapy of oral cancer. Biomater Sci. 2021;9(3):658-662. doi:10.1039/D0BM01898H

10. Ma Z, Jia X, Bai J, et al. MnO 2 Gatekeeper: an Intelligent and O 2 Evolving Shell for Preventing Premature Release of High Cargo Payload Core, Overcoming Tumor Hypoxia, and Acidic H 2 O 2 Sensitive MRI. Adv Funct Mater. 2017;27(4):1604258. doi:10.1002/ adfm. 201604258 
11. Yu Z, Zhou P, Pan W, Li N, Tang B. A biomimetic nanoreactor for synergistic chemiexcited photodynamic therapy and starvation therapy against tumor metastasis. Nat Commun. 2018;9(1):5044. doi:10.1038/s41467-018-07197-8

12. Li J, Li Y, Wang Y, et al. Polymer prodrug-based nanoreactors activated by tumor acidity for orchestrated oxidation/chemotherapy. Nano Lett. 2017;17(11):6983-6990. doi:10.1021/acs. nanolett.7b03531

13. Zhu Y, Shi H, Li T, et al. A dual functional nanoreactor for synergistic starvation and photodynamic therapy. ACS Appl Mater Interfaces. 2020;12(16):18309-18318. doi:10.1021/acsami.0c01039

14. Fan W, Lu N, Huang P, et al. Glucose-responsive sequential generation of hydrogen peroxide and nitric oxide for synergistic cancer starving-like/gas therapy. Angew Chem Int Ed. 2017;56 (5):1229-1233. doi:10.1002/anie.201610682

15. Urabe F, Patil K, Ramm GA, Ochiya T, Soekmadji C. Extracellular vesicles in the development of organ-specific metastasis. J Extracellular Vesicles. 2021;10(9):458. doi:10.1002/jev2.12125

16. van Niel G, D'Angelo G, Raposo G. Shedding light on the cell biology of extracellular vesicles. Nat Rev Mol Cell Biol. 2018;19 (4):213-228. doi:10.1038/nrm.2017.125

17. Raposo G, Stoorvogel W. Extracellular vesicles: exosomes, microvesicles, and friends. J Cell Biol. 2013;200(4):373-383. doi:10.1083/ jcb. 201211138

18. Pitt JM, Kroemer G, Zitvogel L. Extracellular vesicles: masters of intercellular communication and potential clinical interventions. J Clin Invest. 2016;126(4):1139-1143. doi:10.1172/JCI87316

19. Robbins PD, Dorronsoro A, Booker CN. Regulation of chronic inflammatory and immune processes by extracellular vesicles. $J$ Clin Invest. 2016;126(4):1173-1180. doi:10.1172/JCI81131

20. Robbins PD, Morelli AE. Regulation of immune responses by extracellular vesicles. Nat Rev Immunol. 2014;14(3):195-208. doi:10.1038/nri3622

21. van der Pol E, Böing AN, Harrison P, Sturk A, Nieuwland R. Classification, Functions, and Clinical Relevance of Extracellular Vesicles. Pharmacol Rev. 2012;64(3):676-705. doi:10.1124/ pr.112.005983

22. Cassetta L, Pollard JW. Tumor-associated macrophages. Curr Biol. 2020;30(6):R246-R248. doi:10.1016/j.cub.2020.01.031

23. Wang J, Li D, Cang H, Guo B. Crosstalk between cancer and immune cells: role of tumor-associated macrophages in the tumor microenvironment. Cancer Med. 2019;8(10):4709-4721. doi:10.1002/ cam4.2327

24. Wei C, Yang C, Wang S, et al. Crosstalk between cancer cells and tumor associated macrophages is required for mesenchymal circulating tumor cell-mediated colorectal cancer metastasis. Mol Cancer. 2019;18(1):64. doi:10.1186/s12943-019-0976-4

25. Deng X, Liang H, Yang W, Shao Z. Polarization and function of tumor-associated macrophages mediate graphene oxide-induced photothermal cancer therapy. $J$ Photochem Photobiol B. 2020;208:111913. doi:10.1016/j.jphotobiol.2020.111913

International Journal of Nanomedicine

\section{Publish your work in this journal}

The International Journal of Nanomedicine is an international, peerreviewed journal focusing on the application of nanotechnology in diagnostics, therapeutics, and drug delivery systems throughout the biomedical field. This journal is indexed on PubMed Central, MedLine, CAS, SciSearch ${ }^{\mathbb{R}}$, Current Contents ${ }^{\mathbb{R}} /$ Clinical Medicine, $^{2}$
26. Xiao H, Guo Y, Li B, et al. M2-Like Tumor-Associated MacrophageTargeted Codelivery of STAT6 Inhibitor and IKK $\beta$ siRNA Induces M2-to-M1 Repolarization for Cancer Immunotherapy with Low Immune Side Effects. ACS Cent Sci. 2020;6(7):1208-1222. doi:10.1021/acscentsci.9b01235

27. Noy R, Pollard JW. Tumor-Associated Macrophages: from Mechanisms to Therapy. Immunity. 2014;41(1):49-61. doi:10.1016/ j.immuni.2014.06.010

28. Li C-X, Zhang Y, Dong X, et al. Artificially Reprogrammed Macrophages as Tumor-Tropic Immunosuppression-Resistant Biologics to Realize Therapeutics Production and Immune Activation. Adv Mater. 2019;31:1807211. doi:10.1002/ adma.201807211

29. Liang C, Bai X, Qi C, et al. Electron-stabilized polymeric micelles potentiate docetaxel therapy in advanced-stage gastrointestinal cancer. Biomaterials. 2021;266:120432. doi:10.1016/j. biomaterials.2020.120432

30. Nie W, Wu G, Zhang J, et al. Responsive Exosome Nano-bioconjugates for Synergistic Cancer Therapy. Angew Chem Int Ed. 2020;59 (5):2018-2022. doi:10.1002/anie.201912524

31. Tang -T-T, Lv -L-L, Wang B, et al. Employing Macrophage-Derived Microvesicle for Kidney-Targeted Delivery of Dexamethasone: an Efficient Therapeutic Strategy against Renal Inflammation and Fibrosis. Theranostics. 2019;9(16):4740-4755. doi:10.7150/ thno. 33520

32. Castano AP, Mroz P, Hamblin MR. Photodynamic therapy and anti-tumour immunity. Nat Rev Cancer. 2006;6(7):535-545. doi: $10.1038 / \mathrm{nrc} 1894$

33. Li J, Kataoka K. Chemo-physical Strategies to Advance the in Vivo Functionality of Targeted Nanomedicine: the Next Generation. $J \mathrm{Am}$ Chem Soc. 2021;143(2):538-559. doi:10.1021/jacs.0c09029

34. Ojha T, Pathak V, Shi Y, et al. Pharmacological and physical vessel modulation strategies to improve EPR-mediated drug targeting to tumors. Adv Drug Deliv Rev. 2017;119:44-60. doi:10.1016/j. addr.2017.07.007

35. Jing $\mathrm{X}$, Zhi $\mathrm{Z}$, Jin $\mathrm{L}$, et al. $\mathrm{pH} /$ redox dual-stimuli-responsive cross-linked polyphosphazene nanoparticles for multimodal imaging-guided chemo-photodynamic therapy. Nanoscale. 2019;11 (19):9457-9467. doi:10.1039/C9NR01194C

36. Xu T, Ma Y, Yuan Q, et al. Enhanced Ferroptosis by Oxygen-Boosted Phototherapy Based on a 2-in-1 Nanoplatform of Ferrous Hemoglobin for Tumor Synergistic Therapy. ACS Nano. 2020;14 (3):3414-3425. doi:10.1021/acsnano.9b09426

37. Rayamajhi S, Nguyen TDT, Marasini R, Aryal S. Macrophagederived exosome-mimetic hybrid vesicles for tumor targeted drug delivery. Acta Biomaterialia. 2019;94:482-494. doi:10.1016/j. actbio.2019.05.054
Journal Citation Reports/Science Edition, EMBase, Scopus and the Elsevier Bibliographic databases. The manuscript management system is completely online and includes a very quick and fair peer-review system, which is all easy to use. Visit http://www.dovepress.com/ testimonials.php to read real quotes from published authors. 